\title{
A Cross-linguistic Perspective on Questions in German and French Adult Second Language Acquisition"
}

\author{
Solveig Chilla (Heidelberg) and Matthias Bonnesen (Hamburg)
}

\begin{abstract}
Several studies have been conducted to try and understand and explain the morphological and syntactic aspects of adult second language acquisition (SLA). Two prominent hypotheses that have been put forward concerning late L2 speakers' knowledge of inflectional morphology and of related functional categories and their feature values are the Impaired Representation Hypothesis (IRH) and the Missing Surface Inflection Hypothesis (MSIH).

The cross-linguistic comparison of the acquisition of questions in German and French provided in this study offers a new perspective to differences and similarities between first language acquisition (FLA) and adult SLA. Comparing a Germanic and a Romance L2, differing not only in their overall linguistic properties (such as i.e. OV/VO, V2, clitics), but explicitly in the formation and regularities of questions, we present striking similarities in adult SLA, and irrespective of the first and the second languages and of instructed versus noninstructed learning. The investigation of the adult SLA of morphological and structural aspects of questions in French and German strengthens the assumption that the acquisition of morphology and syntax is connected in French and German FLA but is disentangled in adult SLA. Our data reveal variability of question syntax, and with the syntactic position of the verb in particular. Instead of discovering the correct position of the verb at a certain stage of acquisition which can be accounted for by parameter setting in FLA, the adult learners gradually approach the target word order but still exhibit a great deal of variation after several years of exposure to the L2.

The findings provided here contradict the predictions of the MSIH (Prévost/White 2000; Ionin/Wexler 2002; among others), for not only morphological features, but syntactic finiteness of finiteness are problematic in adult SLA, and that the Impairment Representation Hypothesis (IRH) (Beck 1998; Eubank 1993/1994; among others) accounts for these differences in first and second language acquisition. IRH and FDH mirror our findings, by predicting the use of (domain-general) strategies instead of agreement or feature checking mechanisms.
\end{abstract}

\section{Introduction}

Several researchers claim that the age of onset (AO) when acquiring a second language affects, among other domains, the acquisition of grammar. Particularly if the AO to the second language is set with or beyond puberty (Lenneberg 1967) - this is generally referred to as adult SLA - fundamental differences between SLA and FLA have been observed. BleyVroman (1989) mentions characteristics such as fossilization, importance of instruction, variation in success, course and strategies, and goals. Two years later, Meisel (1991)

\footnotetext{
* This study was carried out as a cooperation of two research projects directed by Jürgen M. Meisel and Monika Rothweiler within the Collaborative Research Center on Multilingualism at the University of Hamburg, funded by the Deutsche Forschungsgemeinschaft (German Science Foundation). We thank Jürgen Meisel, Monika Rothweiler and the (anonymous) reviewers for their useful comments.
} 
summarizes the differences as follows: for adult SLA, the ultimate level of attainment is limited, the rate of acquisition slower, intraindividual differences are stronger, acquisitional patterns discontinuous and there is a lack of parameter setting (see also Meisel 1995, 2009 and White 2003 for an overview). Furthermore, authors such as Lardiere (1998, 2003) propose that, unlike in FLA, syntactic and morphological features are separated in adult SLA. Taken together, these fundamental differences between FLA and SLA have been captured as the Fundamental Differences Hypothesis (FDH).

A possible neurobiological explanation for the differences lies in the assumption of so-called sensitive phases resulting from maturational changes to the human Language Making Capacity (LMC). Given sufficient and adequate input, these sensitive phases lead to the successful development of grammar during childhood. This suggests that the necessary basis for an ultimate native-like competence in grammar has been laid by a certain age (see Lenneberg 1967; Hyltenstam/Abrahamsson 2003 for an overview). As Meisel (2009: 7) argues, the "fade out" of optimal phases for grammar development affects both parameterized principles of Universal Grammar (UG) and language-specific learning mechanisms. Within a modified version of the critical period hypothesis (CPH; Meisel 2007, 2008), the idea of "multiple sensitive periods" (Locke 1997) and the lack of concrete neural evidence for a definitive cut-off point have been integrated. It has been proposed that the observed differences between FLA and SLA reflect neural maturation and, as a consequence, underlying grammatical competence (Meisel 2009). Further evidence is provided by neurological studies. While early functional magnetic resonance imaging (fMRI) studies provided evidence that L1 and L2 processing activates the same basic neural circuits (cf. Chee/Tan/Thiel 1999; Hernandez/Martinez/Kohnert 2000, among others), newer studies clearly indicate that the use of an L2, in contrast to L1, results in greater individual variation with respect to the activated areas in the brain and in a considerably stronger activation of these areas (cf. e. g. Rueschemeyer/Fiebach/Kempe/Friederici 2005).

With respect to syntax, the studies of Wartenburger/Heekeren/Abutalebi/Cappa/Villringer/Perani and Saur/Baumgaertner/Moehring/Buechel/Bonnesen/Rose/Musso/Meisel (2009) are particularly relevant. Both analyzed brain activation of L1 speakers and highly proficient late L2 speakers while performing syntactic judgement tasks. Both analyzed brain activation of L1 speakers and highly proficient late L2 speakers while performing syntactic judgment tasks and found that L2 speakers showed increased activation of several cerebral areas. Interestingly, an early bilingual group ( $\mathrm{AO}<3$ years for both languages) was also investigated in the Saur et al. study. For this group, no significant differences were found in brain activation between the two languages; neither of the languages led to greater activation than the other. This observation can be accounted for when it is assumed that these learners have, in contrast to the late bilinguals ( $\mathrm{AO}$ to the $\mathrm{L} 2>12$ years), two first languages. This does not entail, however, that we claim that neurocognitive or maturational changes may be linearly deduced from the language performance of different populations (cf. Knudsen 2003, 2004; Meisel 2009; Tracy 2009), at least not with respect to the acquisition of questions.

Even though the FDH presupposes fundamental differences between FLA and SLA, the developmental pathways also share similarities. L2 learners construct their utterances using phrases (DP, VP, PP...) (cf. Chomsky 1957; Pienemann 1998) and are aware of concepts like subject and object. But in contrast to L1 speakers, they may lack certain hierarchical structures, as proposed in Clahsen/Meisel/Pienemann (1983), as well as feature checking. In FLA, hierarchical structures and feature checking as a motivation for movement can account for the utterances and for why certain positions require finite verbs while others are nonfinite. In late L2 performance, the overt appearance of grammatical features seems to be 
somewhat optional, as may be seen from the use of finite and non-finite verbs in obligatorily finite contexts.

Several studies have been conducted to try and understand and explain the morphological and syntactic aspects of German and French SLA. Two prominent hypotheses that have been put forward concerning late L2 speakers' knowledge of inflectional morphology and of related functional categories and their feature values are the Impaired Representation Hypothesis (IRH) and the Missing Surface Inflection Hypothesis (MSIH).

The IRH states that L2 grammar is "either globally or locally [impaired], at the level of functional categories or features" (Prévost/White 2000: 110). The most straightforward IRH theories follow Meisel's (1997) study on German and French, stating that late L2 grammars completely lack agreement and that verb placement is not related to finiteness. It follows from these assumptions that SLA is not constrained by Universal Grammar (UG), which is subject to the critical period, and that L2 learners do not have access to parameter (re-)settings, but may rely on their L1 parameter settings. SLA follows linear sequencing, i. e. strategies. Beck (1998) and Eubank (1993/1994) add a less extreme IRH view by proposing local instead of complete impairment. Taken together, the IRH and FDH predict the use of (domain-general) strategies rather than agreement or feature checking mechanisms. With respect to the two languages in our study, it follows that on this view, the acquisition of questions in L2 German should be independent from the acquisition of subject-verb-agreement/finiteness or V2 and from subject verb-agreement/finiteness and subject clitics as agreement markers (Kaiser 1994; Roberge 1986) in French.

The MSIH (Prévost/White 2000; Ionin/Wexler 2002; Haznedar 2003) on the other hand, states that the knowledge of abstract syntactic properties and of morpho-phonological forms develops independently. On this view, L2 learners are unconsciously aware of the functional projections and feature values underlying tense and agreement. Concerning the acquisition of questions, L2 learners would be expected to master the structural requirements of questions in German and French, but fail to produce finite verb forms in obligatorily finite contexts. Thus, the computational system itself would remain unaffected, but the realization of the surface morphology would remain problematic, showing difficulties in the mapping from syntax to morpho-phonology (i. e. Lardiere 1998; Prévost/White, 2000). Prévost and White (2000) summarize: "variability in adult L2 performance does not reflect a deeper lack of functional categories or features associated with tense and agreement. Rather, L2 learners have difficulties with the overt realization of morphology" (ibid.: 104), but "syntactic consequences of finiteness are known to learners" (ibid.: 119).

In our study, we conduct a cross-linguistic comparison of late L2 acquisition of questions in German and French. Irrespective of the language under investigation, this may provide further insights into the differences and similarities between FLA and SLA, particularly into the aspects of grammar affected. The focus on question acquisition in two typologically different languages is of specific interest as French and German not only differ in their overall linguistic properties (such as, for instance, OV/VO word order, V2 position, and the use of clitics), but also explicitly in question formation and syntax. Questions refer to the CP layer and thus rely on certain properties in FLA that may not be indicative of SLA (see below). As such, our comparative study will allow for conclusions about the effect of the L1(s) on the development of the L2 in a specific grammatical domain (questions) as well as about the similarities and differences between the FLA and adult SLA of a specific language, which in turn may be illuminating with respect to the FDH, which states that fundamental differences between FLA and adult SLA exist.

The study specifically investigates the adult SLA of morphological and structural aspects of questions in French and German. A new perspective on SLA research is provided by the 
systematic study of question acquisition in adult SLA of French. Evidence so far suggests that the acquisition of morphology and syntax (on the CP-layer) is connected in French and German FLA but is disentangled in adult SLA (see below). Finally, we aim at detecting crosslinguistic similarities and differences questioning the current models of SLA.

In the following sections, we will first sketch the question syntax for German and French, focusing on cross-linguistic differences and similarities. We will then provide a summary of previous studies on question acquisition from within FLA and adult SLA, followed by our own study. In a final section, we will discuss our results in light of three hypotheses for adult SLA.

\section{Questions in French and German}

French is considered a VO language and offers several ways to form direct questions (cf. Confais 1980; Hirschbuehler/Labelle 1994; Rizzi 1996; Rizzi/Roberts 1989; among others). German, however is an OV and verb-second (V2) language. For subordinate clauses, den Besten (1977) proposes that the finite verb occupies the same position as the complementizer given their complementary distribution. In direct questions, the finite verb is placed before the subject, giving rise to subject-verb inversion. From a generative point of view (Chomsky 1986, 1995; Rizzi 1996), subject-verb inversion is explained by the movement of the verb to a position before the subject $\left(\mathrm{C}^{\circ}\right)$ while leaving a trace $t$ in its base position:

$$
\left[{ }_{C P}(\text { why })\left[{ }_{C} d o\right]\left[{ }_{T P} \text { you }\left[_{T^{\circ}} t\right]\left[_{V P}\left[V_{V^{\circ}} \text { eat }\right]\left[_{D P} \text { the banana }\right]\right]\right]\right. \text { ? }
$$

Since the moved verb comes from a position $\left(\mathrm{T}^{\circ}\right)$ which is finite, only finite verbs occur before the subject. Considering wh-questions, French and German employ the same word order with simple verbs as in (2):

$$
\begin{array}{lll}
\text { (a) wo } & \text { ist } & \text { das ende der welt? (German) } \\
\text { (b) où } & \text { est } & \text { le bout du monde? (French) } \\
\text { [where } & \text { is } & \text { the end of the world] }
\end{array}
$$

For German, if the direct question contains a wh-phrase, it is located in the specifier of the $\mathrm{CP}$, the first position of the sentence. Both the wh-phrase, if present, and the verb carry a question feature $\mathrm{Q}$. The movement of the verb to $\mathrm{C}^{\circ}$ (and of the wh-phrase to Spec $\mathrm{CP}$ ) is triggered by the need for feature checking. The Q-feature must be checked in a specifier-head relation in the CP (Rizzi 1996).

The same as shown in (1) for English holds for German: with the exception of so-called echoquestions which make use of declarative word order, direct question formation in German requires subject-verb inversion. This includes the formation of both yes/no questions and whquestions.

By contrast, inversion is not attested in yes/no questions in spoken French, neither with clitic nor with non-clitic subjects (Behnstedt 1973; Bonnesen/Meisel 2005; Meisel/Elsig/Bonnesen 2011). The question is often formed by means of intonation only, without any syntactic markers, making use of declarative word order (SVO). Another way of producing yes/no questions in French is to add the question particle est-ce que to a declarative construction in sentence-initial position without changing the word-order, as in (3):

$$
\begin{array}{ll}
\text { [est-ce que] } & \text { th partes? } \\
{[\mathrm{Q}} & \text { you leave] }
\end{array}
$$

However, Behnstedt (1973) reports that yes/no est-ce que questions occur at a rate of only $4.7 \%$. Theoretically speaking, also wh-questions may be formed by means of the est-ce que question marker, but such constructions are rare in spoken French (Bonnesen 2008). In this 
case, the question marker is placed between the wh-word and the subject (e. g. où [est-ce que] Jean va? [where Q Jean goes]) and the word order of declaratives is used.

Also in terms of pronouns, German and French differ greatly. In German, pronouns are free elements and inversion is obligatory in all direct wh- and yes/no questions, regardless of the status of the subject. This is illustrated in (4):
(a) wo
wohnt er/John?
[where
lives he/John]
(b) kommt
er/John zur feier?
[comes
he/John to-the party]

In contrast, the French subject pronouns je ('I'), tu ('you'), il ('he'), etc., are clitic elements or, according to some authors, agreement markers (verbal affixes) (for the latter view, see Kaiser 1994, Kaiser/Meisel 1991; Roberge 1986; among others). In certain contexts, such as with yes/no questions, inversion is allowed with subject clitics (SCLs) but not with non-clitic subjects (Rizzi/Roberts 1989; Confais 1980: 174-184). Consider the examples in (5):

(a) *estle facteur déjà passé?

[is the postman already gone]

(b) est-il déjà passé?

[is he already gone]

Inversion in questions is obligatory with subject clitics in standard French. However, authors like Confais (1980: 174) and Behnstedt (1973) claim that inversion is rarely still heard in present-day spoken French and is mainly associated with written language. Bonnesen and Meisel (2005) and Meisel et al. (2011) present a more detailed picture. They point out that in wh-questions with clause-initial wh-phrases inversion is invariably used in combination with non-clitic subjects but hardly ever with clitic subjects. However, a clitic pronoun often cooccurs with a non-clitic subject, i. e. a DP-subject (DPS), in spoken French (cf. Kaiser 1994; Sankoff 1982). Hence, the common word order patterns in spoken French are wh-V-DPS (consider, for example, où habite ton père? [where lives your father], wh-SCL-V (où il habite? [where he lives]) and wh-SCL-V-DPS (où il habite ton père? [where he lives your father]). To account for the observation that DP and clitic subject occur in a different position, Bonnesen and Meisel follow the verbal-affix approach to SCLs. On this view, the clitics are strictly attached to the preverbal position as prefixes. When the verb moves to a position before the subject $\left(\mathrm{C}^{\circ}\right)$, the clitic moves along with it. In contrast, a DP subject remains in its position (SpecTP) and subject-verb inversion occurs when the verb moves to $\mathrm{C}^{\circ}$ in whquestions. This is shown in (6):

$$
\begin{aligned}
& \text { (a) }\left[{ }_{\mathrm{CP}} \text { où }\left[\mathrm{C}^{\circ} \text { tu vas }\right]\left[{ }_{\mathrm{TP}}\left[\mathrm{T}^{\circ} \mathrm{t}\right] \ldots\right]\right] \text { ? } \\
& {[\text { where you go }]} \\
& \text { (b) }\left[{ }_{\mathrm{CP}} \text { où }\left[\mathrm{C}^{\circ} \text { va }\right]\left[\mathrm{TP} \text { ton père }\left[\mathrm{T}^{\circ} \mathrm{t}\right] \ldots\right]\right] \text { ? } \\
& {[\text { where goes your father }]}
\end{aligned}
$$

In wh-questions with complex verb phrases, the observed word order in spoken French when a clitic is used is wh-SCL-Aux-V: as with questions with simple verb phrases, inversion does not occur. Inversion is, however, possible when the subject is a DP and therefore located in sentence-final position. Though possible, these constructions are rare in spoken French.

Wh-questions may also be formed as wh-in-situ questions. These are characterised by a declarative word order with the wh-word in sentence-final position (e. g. Jean va où? [Jean goes where]). Note that in contrast to questions with declarative word order in German, this 
kind of question is not an echo-question and occurs in spoken French at a rate of $15.6 \%$ (Coveney 2002: 188).

Table 1 offers an overview on the syntax of questions in German and French, concentrating on superficially equal structures, which have been marked in italics:

\begin{tabular}{|c|c|}
\hline German (OV/V2) & French (VO) \\
\hline \multicolumn{2}{|c|}{ Yes/no questions } \\
\hline $\begin{array}{l}\text { subject-verb inversion is obligatory } \\
\text { declarative structure possible only in echo- } \\
\text { questions } \\
\text { - }\end{array}$ & $\begin{array}{l}\text { no inversion } \\
\text { declarative structure (SVO) generally possible } \\
\text { est-ce que + declarative }\end{array}$ \\
\hline \multicolumn{2}{|c|}{ wh-questions } \\
\hline $\begin{array}{l}\text { inversion is obligatory } \\
- \\
-\end{array}$ & $\begin{array}{l}\text { usual word order with simple VP: } \\
\text { wh-V-DPS (inversion) } \\
\text { wh-SCL-V (no inversion) } \\
\text { usual word order with clitics and complex VP: } \\
\text { wh-SCL-Aux-V } \\
\text { wh-in-situ (no inversion) } \\
\text { wh-[est-ce que]-DPS/SCL-V (no inversion) }\end{array}$ \\
\hline
\end{tabular}

Table 1: An overview on the syntax of questions in German and (spoken) French

\section{Questions in first and second language acquisition of German and French}

Children acquiring German as their L1 grasp the underlying OV-structure immediately, producing utterances with left-branching VPs like (7) in the so-called optional infinitive (OI) stage.

(7) ball pieln! mama ball suchen!] (Hilde, 2;0)

[play ball-INF mama ball search-INF]

As soon as they begin to use verb inflection to mark subject-verb agreement (SVA), children place the finite verb in V2 position (cf. Clahsen 1988; Clahsen/Penke 1992; Wexler 1994). There are nearly no instances of infinitives in V2. Once subordinate clauses are used (shortly after the acquisition of finiteness and V2 in declarative main clauses and the production of questions), cases of V2 instead of verb-last (VL) position in subordinate clauses are extremely rare (cf. Rothweiler 1993:141).

As for the acquisition of questions, several researchers observe target-like constructions as soon as questions are first produced. Children consistently employ inversion in wh- and yes/no questions throughout their language development. The instances where an SVO structure is used to form a yes/no question can be interpreted as appropriate echo-questions. Authors like Bonnesen (2008), Clahsen/Penke/Parodi (1993/1994) and Fritzenschaft/Gawlitzek-Maiwald/Tracy/Winkler (1990) propose a two-stage developmental pattern for the acquisition of structural requirements of wh-questions based on a MLU comparison (MLU=mean length of utterances, based on the number of morphemes per utterance). In the first stage, only wo/was (ist) + NP/DP [where/what is] questions are 
produced. The MLU at this stage is about 1.75 (age 2;0) and questions do not yet appear productively. This structure is produced for several months (cf. Bonnesen 2008; Wode 1983; among others). The verb is sometimes omitted, as illustrated in (8):

$\begin{array}{ll}\text { wo } & \text { der hut? (Pierre, 3;01,25) (Bonnesen 2008: 176) } \\ \text { [where___ the hat] }\end{array}$

In the second stage (MLU of 1.75-2.75), questions are produced productively and adult-like. A precursor to this stage, however, is the acquisition of finiteness/SVA. As a consequence, errors pertaining to non-finite verbs and subject-verb agreement hardly ever occur in questions in FLA. Furthermore, with inversion, the inverted verb, coming from a finite position $\left(\mathrm{T}^{\circ}\right)$, carries the correct SVA morpheme. Apart from the occasional omission of whwords (cf. Bonnesen 2008; Clahsen et al. 1993/1994; Fritzenschaft et al. 1990; van Kampen 1997; Tracy 1994), errors are hardly attested in the FLA of questions. There is no stage in which the children use (wh-) questions but do not invert subject and finite verb. As soon as they produce questions with verbs, the verb is moved to $\mathrm{C}^{\circ}$. An absence of inversion in early stages of language acquisition is due to the omission of the verb as in (7).

Moreover, sentences with V3 placement are rare in FLA German, and most of these structures can be interpreted as (temporal) adjuncts to the AgrP, occurring most often in repetitive storytelling, as shown in (9):

$$
\text { und dann der mann kauft eis }
$$

[and then the man buys ice-cream]

In sum, typical characteristics for the FLA of German questions are:

- inversion from the first questions onwards, structural patterns are correct from the first occurrences onwards

- wh-questions appear consistently with V2

- no V3 or V4 patterns

- no subject-verb agreement errors

- no infinitives in wh-questions

- $\quad$ subject omissions in yes/no-questions are rare;

- no subject omissions in wh-questions.

For adult learners of German as an L2, the picture is completely different. According to ZISA (Clahsen et al. 1983), a study which is cited regularly when discussing adult SLA of German and whose results have been reanalyzed by several other authors (e. g. Clahsen/Muysken 1986, 1989; Parodi 1998; Prévost/White 2000), the acquisitional stages may be characterized as follows (cf. Pienemann 1998):

Stage $\mathrm{x}=$ Canonical Order SVO

Stage $\mathrm{x}+1=$ Adverb Preposing $(\mathrm{ADV})[=\mathrm{XSV}]$

Stage $\mathrm{x}+2=$ Verb Separation (SEP) [=sentence bracket $]$

Stage $\mathrm{x}+3=$ Inversion (INV) [=V2-property]

Stage $\mathrm{x}+4=$ Verb Final (V-END)[=correctly formed subordinate clauses]

This sequence has largely been corroborated (with the exception of the commutation of the last two stages) by DiGS (Diehl/Christen/Leuenberger/Pelvat/Studer 2000), "Deutsch in 
Genfer Schulen" ('German in schools of Geneva'), an extensive study using written production data of about 100 children and adolescents from age 9 to 18 .

Production data of late L2 learners of German shows difficulties with question formation. According to Felix (1978), learners do not use inversion in wh-questions in the early stages of development. This result is supported by the findings of Clahsen et al. (1983) concerning later developmental stages. In their cross-sectional study, the authors investigate the language acquisition of 45 Italian, Spanish and Portuguese second language learners of German. Each participant was recorded only once. The learners had had contact with German for periods of time ranging from less than one year to 17 years. The authors observe that the structure of questions varies among different learners as well as interindividually. All possible combinations of word order are attested. Even those learners who had had contact with German for more than ten years did not necessarily use inversion in questions. Consider, for example, Eliseo I (12 years in Germany), cf. (10).
(a)
warum du muss
schule so
so?
[why you must school like this like this]
(b)
warum du hier arbeit?
[why you here work]
(c) warum du nix zu (dazu) sag?
[why you nothing to (this) say]

(Clahsen et al. 1983: 146, 339f.)

Eliseo's data exhibit subject-verb agreement errors, as shown in (10) - a pattern hardly ever found in FLA. Furthermore, the authors argue that some learners use specific strategies such as omitting the subject or the verb in order to avoid the difficulties associated with inversion.
(a) wer das? (Antonio, S. 11 years of exposure)
[who this]
(b) und warum wir so viel miete? (Antonio, S. 11 years of exposure)
[and why we so much rent]
(c) wie lang arbeit? (Pascua S. 7 years of exposure)
[how long work]
(d) was machen? (Pascua S. 7. years)
[what do-INF]

(Clahsen et al. 1983: 146)

After 7 and 11 years of exposure to the L2, verb omissions in questions still occur. In contrast, such errors are attested in FLA only in very early stages. Furthermore, only adult L2 learners produce subject omissions in wh-questions. According to Clahsen et al. (1983), these omissions represent a precursor to the acquisition of inverted wh-questions, the last developmental stage. The learners deliberately reduce the number of contexts in which inversion is obligatory. In a further longitudinal study (Zisa Group 1983-1985), the authors argue that several stages exist within the adult SLA of German questions. The early stages are characterized by the absence of inversion. The first forms of inversion occur in yes/noquestions. Later on, after a period of occasional wh-questions with inversion, inversion is regularly attested.

FLA of questions in French seems to be comparatively straightforward. As in German, the only typical error is the occasional omission of a wh-word in the early stages. Furthermore, in 
studies such as Bonnesen (2008) and Mueller (1993) for bilingual FLA German/French or Crisma (1992) and de Cat (2000) for FLA, it is observed that the subject is sometimes dropped in yes/no-questions. However, subject omissions are never attested in wh-questions (see Rizzi, 1992 for a possible explanation). With respect to the position of the wh-word in FLA, findings contradict each other (for an overview, see Prévost 2009: 347-352). Some children begin with initial wh-words (cf. Bonnesen 2008; Crisma 1992) while others prefer wh-in-situ questions (cf. de Cat 2000; Hamann 2000; Jakubowicz/Strik 2008; Oiry/Demirdache 2006; Zuckerman/Hulk 2001). Since both positions are possible, the children's constructions reflect the target language in both cases.

As far as the subject-verb order is concerned, the children produce the structure of the target language from the beginning onwards. They use initial wh-words with the word order described in Bonnesen and Meisel (2005): a DPS, when occurring without a co-referent clitic, appears exclusively in post-verbal position (see examples in 5), whereas clitics nearly always occur in preverbal position (cf. also Bonnesen 2008). It is important to note that apart from occasional omissions of a wh-word or the subject in yes/no-questions in early stages of acquisition, errors are not attested. Children acquiring French use the correct word order from early on. Non-finite verbs and subject-verb agreement errors in questions do not occur.

Additionally, inversion in yes/no-questions is not attested. Est-ce que-yes/no-questions are produced only rarely, both in FLA as well as in adult speech. One of the two French/German bilingual FLA children whose data are analyzed in Bonnesen (2008) does not produce any est-ce que-yes/no-questions at all. In the data of the other child, yes/no-questions with est-ce $q u e$ are attested at a rate of $6.9 \%$. As in adult speech, intonational yes/no-questions are produced at a rate of more than $90 \%$.

Considering error types, the following picture reveals itself for French FLA:

- $\quad<1 \%$ post-verbal clitics

- hardly any questions without SCLs

- clitic doubling occurs at a rate of $81.5 \%$

- $\left(\mathrm{qu}^{\prime}\right)$ est-ce que attested with finite verbs only

- est-ce que-questions rarely occur (in FLA) (0-6.9\%).

First indications that further research was imperative comes from the studies of French SLA by authors like Granfeldt and Schlyter (2004), Meisel et al. (2011) and Prévost (2009). Their findings lead to the impression that FLA and adult SLA may differ in several aspects, such as the status of the subject or the rate of verb omissions in yes/no questions. Granfeldt and Schlyter (2004) show that in SLA performance, clitic subjects are sometimes separated from their verbs by means of adverbs and are produced without finite verbs and in post-verbal position.

Taken together, the syntax of questions in German and French differs in several aspects. Whereas German question formation is relatively rigid, leaving little or no room for variability, the French language allows (for) a variety of possible structures . From a crosslinguistic perspective to language acquisition, FLA and SLA differ in several ways with respect to both word order and finiteness. For example, even though French question syntax offers a wide range of possibilities, L1 learners use target-like constructions from the beginning. A parallel picture is found for German, even though the rather strict rules of German question formation may be acquired in a different way. Whereas verbal finiteness is a precursor of wh-questions for FLA in both languages, late L2 learners frequently produce whquestions with and without inversion, irrespective of the finiteness of the verb. Moreover, 
non-finite verbs occur in finite questions, again something which is characteristic of L2 acquisition (Prévost 1997; Bartning/Schlyter 2004).

\section{The Study}

The present study is a cross-linguistic investigation of adult SLA of questions in French and German, focusing on morphological and structural aspects. Both the cross-linguistic perspective and the systematic study of adult SLA of questions in French are novel aspects to the discussion of SLA and FLA.

\subsection{Method}

We analyse two corpora of SLA, namely the ZISA for German and the Myles-Corpus for French. The grammar of questions is related to the CP-layer, and is therefore particularly informative with respect to investigating fundamental differences in FLA and SLA. Questions in both German and French follow strict regularities, and are obligatorily finite, both on the sentence and on the verbal level. Grouping the learners by exposure time, the analysis thus includes: (i) a counting of all wh- and yes/no-questions in the corpora, (ii) a detailed analysis of question types and tokens in both corpora, and (iii) an analysis of the finiteness and the position of the (finite) verb in questions, and (iv) language-specific features, such as clitics and est-ce que-questions in French. All these aspects are discussed with respect to targetlanguage and language-specific as well as language-unique use.

\subsection{Adult SLA of Questions in French}

The French adult SLA data were provided by the cross-sectional study conducted by Myles (2001-2002). Since these learners began learning French around the age of 11, we assume that they can already be classified as adult SLA (cf. Meisel 2007). In these data, "three groups of twenty learners in each of years 9, 10 and 11 (in their 3rd, 4th and 5th year respectively of learning French in the UK educational context; age 13-14, 14-15, 15-16 respectively) in a local secondary school have been tested." (Cited from: http://www.flloc.soton.ac.uk/newcastle/index.html, accessed December 14, 2012). We analyzed the data of the 14 learners in year nine 01I9SAR, 02I9FLO, 03I9ADR, 04I9LAR, 05I9JAM，06I9SAR，0719FLO, 0819ADR，0919LAR，11I9SAR，12I9FLO, 13I9LAR, 17I9FLO and 20I9ALI, who were chosen because they produced the highest number of questions with verbs. Table 2 offers an overview of the adult SLA data.

\begin{tabular}{lccc}
\hline Name (group) & Number of questions & Number of wh-questions & Number of yes/no-questions \\
\hline 01I9SAR & 18 & 14 & 4 \\
\hline 02I9FLO & 14 & 14 & 0 \\
\hline 03I9ADR & 11 & 11 & 10 \\
\hline 04I9LAR & 18 & 8 & 3 \\
\hline 05I9JAM & 15 & 12 & 5 \\
\hline 06I9SAR & 19 & 14 & 2 \\
\hline 0719FLO & 23 & 21 & 11 \\
\hline 0819ADR & 20 & 9 & 10 \\
\hline 0919LAR & 20 & 10 & 6 \\
\hline 11I9SAR & 6 & 0 & \\
\hline
\end{tabular}


Solveig Chilla and Matthias Bonnesen: A cross-linguistic perspective on questions in German and13 French adult second language acquisition

\begin{tabular}{lccc}
\hline 12I9FLO & 10 & 9 & 1 \\
\hline 13I9LAR & 26 & 4 & 22 \\
\hline 13I9LAR & 10 & 0 & 10 \\
\hline 20I9ALI & 14 & 3 & 11 \\
\hline Total & 224 & 129 & 95 \\
\hline
\end{tabular}

Table 2: Data overview and number of questions in French adult second language acquisition

In the preceding section, we have seen from the literature that errors rarely occur in the acquisition of questions in French FLA. This does not hold for adult SLA, however. In the following, we will show some major differences compared to FLA. First, we focus on the use of the subject.

\subsection{The status and position of the subject in French adult SLA}

Only 45 SCLs out of a total of 228 subjects occur in our adult SLA corpus, i. e. $19.7 \%$ of the subjects are clitics, while the other $80.3 \%$ are DPs. Five of the 14 learners (01I9SAR, 03I9ADR, 09I9LAR, 10I9JAM, 11I9SAR) do not use SCLs in questions at all. Two other learners use only one SCL, which represents less than $10 \%$. Clitic doubling in questions occurs at a rate of merely $3.1 \%$ (7/224). Three of these constructions represent instances of complex inversion, a construction not attested in spoken French (cf. Behnstedt 1973). These occurrences may be due to language instruction. The low rate of SCLs and clitic doublings in adult SLA can be accounted for by assuming that, in contrast to FLA, L2 learners do not analyze SCLs as elements of finiteness but rather as DPs, as proposed in Granfeldt and Schlyter (2004). The authors show that SCLs in adult SLA can be separated from the verbs by means of adverbs and that they are produced without finite verbs. This may also account for the low rate of SCLs and clitic doublings. As clitics are not used as subject-verb agreementmarkers, they consequently do not appear as frequently as in FLA. Assuming that SCLs are DPs in adult SLA, one can predict that they will occur without finite verbs and in inversions. Indeed, this is what we find. In fact, some learners produce hardly any SCLs with finite verbs in questions:

(a)

est grande elle? (20I9ALI)

[is big she]

(b) il cheveux courts? (0819ADR)

[he hair short]

In the entire corpus, $12(26.7 \%)$ SCLs in questions appear without a finite verb. Note that these constructions (as in (11)) are also incorrect in their L1, English, and that direct transfer is thus very improbable as the cause for this kind of error. In (12b), the verb is omitted. The learners possibly omit the verb in order to avoid difficulties associated with inversion. Eight of the 14 adult French learners produce questions without verbs. In summary, the verb is omitted in 11 of $84(13.1 \%)$ yes/no-questions and in one of $140(0.7 \%)$ wh-questions.

In addition to the occurrences of SCLs without a finite verb, inversions with subject clitics and complex inversions are also attested:

est elle la fille dans le \# bench@s:d? (05I9JAM)

[is she the girl in the $\mathrm{X}$ ]

(b) comment $t^{\prime}$

appelle il? (06I9SAR)

[how himself calls he] 
(c)

Natalie est elle petit? (06I9SAR)

[Natalie is she small]

All in all, $14(31.1 \%)$ of the 45 SCLs are located in post-verbal position. In sum, 26 of 45 (57.8\%) SCLs do not occur in the position before and adjacent to the finite verb (12 clitics without a finite verb and 14 clitics in post-verbal position).

\subsection{Yes/no-questions adult SLA of French}

Two of the L2 learners always produce est-ce que (01I9SAR: 4, 0719FLO: 2), while another consistently uses est-ce que or qu'est-ce que (04I9LAR: 10) when constructing yes/noquestions:

(a)

est ce que Pierre um petit? (0719FLO)

[Q Pierre (um) small]

(b) qu' est ce que Marie a cheveux courts? (04I9LAR)

[Q Marie has hair short]

Learner 0919LAR produces an invalid phonetic form (is) instead of est-ce que which may be transfer from English due to the phonetic similarities between est-ce que and is.

$$
\text { is Marc manger? (0919LAR) }
$$

[Q Marc to-eat]

Seven out of ten yes/no-questions produced by 0919LAR are constructions such as that in (15). DPS inversion occurs in the remaining three yes/no-questions, which is incorrect. Another learner uses il y a instead of est-ce que as a question marker (16).

(a) il y a um \# manger un sandwich? (0819ADR)

[Q (um) to-eat a sandwich]

(c) il y a acheter au livre? (0819ADR)

[Q to buy at book]

In (14)-(16), the learners produce est-ce que-questions without finite verbs. The learners simply add an item to a declarative in order to mark the construction as a question and thus avoid the difficulty of inversion (cf. Clahsen et al. 1983). In summary, correct or phonetically incorrect forms of est-ce que are produced in 34 (40.5\%) of a total of 84 yes/no-questions. Considering only questions with subjects and verbs, the intonation question is used in 32 $(38.1 \%)$ cases, while inversion appears in $11(13.1 \%)$. Note that the numbers do not add up to $84(100 \%)$, as there are also questions without a subject or a verb. Both clitic and non-clitic subjects occur in inversion and intonation questions: eight DP inversions and three SCL inversions, 24 DP intonation questions and seven clitic intonation questions are produced. DPS inversion is grammatically incorrect in written and spoken French. In contrast, SCL inversion is possible in written French, but hardly ever appears in spoken language. Inversion could also be considered to be a transfer from English. However, more important than speculating about possible transfer is the fact that we find all possible word orders with both clitic and non-clitic subjects and with finite and non-finite verbs. While inversion with subject clitics might occur due to formal language instruction, DPS-inversion is incorrect in both written and spoken French.

\section{5 wh-questions adult SLA of French}

The subject is omitted in only one of the 140 wh-questions in the corpus: 
Solveig Chilla and Matthias Bonnesen: A cross-linguistic perspective on questions in German and15 French adult second language acquisition

qu' est ce que fait? (05I9JAM)

[what make]

Two of the 14 learners produce infinite verbs in each of their qu'est-ce que-questions (0219FLO: 4, 0719FLO: 5), while another (13I9LAR) produces four infinite verbs in his five qu'est-ce que-questions:

(a) qu' est ce que Marie euh faire? (02I9FLO)

[what Marie euh to-do]

(b) qu' est ce que Guillaume manger? (02I9FLO)

[what Guillaume to-eat]

Wh-questions other than qu'est-ce que do not occur with non-finite verbs. Each of these three learners produces finite verbs in other constructions.

Another type of error appearing in qu'est-ce que-questions is the subject-verb inversion. 03I9ADR produces inversion in each of his four qu'est-ce que-questions. This type of error also occurs in the data of learners 05I9JAM and 12I9FLO.
(a) qu' est ce que fait \# l' homme? (03I9ADR)
[what makes the man]
(b) qu' est ce que fait Florence? (05I9JAM)
[what makes Florence]
(c) Pierre qu' est ce que jouer Pierre? (12I9FLO)
[Pierre what to-play Pierre]

The different error types in qu'est-ce que-questions again clearly show that transfer cannot account for certain errors. Furthermore, we find a rich variety of different word orders. The learners produce qu'est-ce que-questions with and without inversion, with the verb being finite and non-finite in both contexts. Both the use of inversion and the occurence of nonfinite verbs in qu'est-ce que-questions cannot be accounted for by language instruction. Feature checking mechanisms as motivation for movement do obviously not operate. The learners do not adhere to one basic structure. The subject and the verb are combined in a rather free manner. As we have shown above, the learners produce non-finite verbs in finite positions as in inversion and in qu'est-ce que-questions. Thus, the production of wh-questions is further evidence that L2 learners do not employ the same hierarchical structures as native speakers. Table 3 provides a summary of the differences between FLA and adult SLA of French.

\begin{tabular}{lll}
\hline $\begin{array}{l}\text { Grammatical } \\
\text { phenomena }\end{array}$ & FLA & adult SLA \\
\hline word order & no wh-DPS-V & wh-DPS-V occurs \\
\cline { 2 - 3 } & no complex inversion & complex inversion appears \\
\cline { 2 - 3 } & no inversion with qu'est-ce que & inversion with qu'est-ce que occurs \\
\cline { 2 - 3 } & $<1 \%$ post-verbal clitics & $31.1 \%$ post-verbal clitics \\
\cline { 2 - 3 } & no inversion in yes/no-questions & inversion in yes/no-questions occurs \\
& $(26 \%)$ \\
\hline
\end{tabular}




\begin{tabular}{|c|c|c|}
\hline \multirow[t]{2}{*}{ kind of subject } & hardly any questions without SCLs & $\begin{array}{l}\text { over } 80 \% \text { of the questions contain a } \\
\text { DPS only }\end{array}$ \\
\hline & $\begin{array}{l}\text { clitic doubling occurs at a rate of } \\
81.5 \%\end{array}$ & clitic doubling occurs at a rate of $3.1 \%$ \\
\hline \multirow[t]{2}{*}{ finiteness } & $\begin{array}{l}\text { no subject clitics in questions } \\
\text { without finite verbs }\end{array}$ & $\begin{array}{l}26.7 \% \text { of the subject clitics in questions } \\
\text { occur without finite verbs }\end{array}$ \\
\hline & $\begin{array}{l}\text { (qu')est-ce que attested with finite } \\
\text { verbs only }\end{array}$ & $\begin{array}{l}\text { (qu')est-ce que without finite verbs; in } \\
\text { some learners exclusively/often }\end{array}$ \\
\hline est-ce que-questions & $\begin{array}{l}\text { est-ce que-questions occur rarely } \\
\text { (in FLA) }(0-6.9 \%)\end{array}$ & $\begin{array}{l}\text { est-ce que is frequently }(40.5 \%) \\
\text { produced }\end{array}$ \\
\hline
\end{tabular}

Table 3: Different types of errors in questions in French FLA and adult SLA

\subsection{Adult SLA of Questions in German}

In the following, we present findings from our own analysis of the adult SLA of questions. We chose longitudinal (Zita, Ana) and cross-sectional (Sita, Miguel, Rosemarie, Francisco, Michele) data from the ZISA-study (Zweitspracherwerb italienischer, portugiesischer und spanischer Arbeiter - second language acquisition (of German) of Italian, Portuguese and Spanish workers, cf. Clahsen et al. 1983), and investigate the first four years of acquisition. All learners were adult immigrants with a romance language background and an age of onset over 15 years of age (Portuguese: Sita, Zita; Spanish: Ana, Miguel, Rosemarie; Italian: Michele). The spontaneous speech samples of approximately 40 minutes each were recorded with a monolingual German interlocutor (Clahsen et al. 1983). With respect to Ana and Zita, we included only the recordings made in Germany and excluded those recorded after remigration. Furthermore, we considered all recordings that contained questions with verbs. Table 4 offers an overview of the German L2 data.

\begin{tabular}{lcrrrr}
\hline Name (group) & $\begin{array}{l}\text { Exposure } \\
\text { (years) }\end{array}$ & $\begin{array}{l}\text { time } \\
\text { questions }\end{array}$ & $\begin{array}{l}\text { of } \\
\text { questions }\end{array}$ & $\begin{array}{l}\text { Number } \\
\text { questions }\end{array}$ \\
\hline Total group 1 & 1 & 81 & 14 & 67 \\
\hline Total group 2 & 2 & 79 & 35 & 44 \\
\hline Total group 3 & $3-4$ & 24 & 24 & 0 \\
\hline total & & 184 & 73 & 111 \\
\hline
\end{tabular}

Table 4: Data overview and number of questions in German adult second language acquisition

All learners except Sita produce wh-questions in their first year of exposure to German. Group 1 produces 80 questions, 67 of which are yes/no-questions (83.8\%). In the second year, the rate of wh-questions increases from $16.3 \%$ to $44.3 \%$.

The SVA correctness rate falls consistently below $75 \%$ (cf. table 5), and the SVA correctness rates in questions do not increase significantly throughout the first three to four years of exposure to German. This finding is even more important, because both cross-sectional and longitudinal data are considered. The individual correctness rates do not contradict this trend: Ana and Zita, for example, reach $61.1 \%$ and $80.5 \%$, respectively, in their first year of exposure, $63.2 \%$ and $75.0 \%$ in their second, and $72.7 \%$ correctness in Zita's third year. 
Solveig Chilla and Matthias Bonnesen: A cross-linguistic perspective on questions in German and17 French adult second language acquisition

\begin{tabular}{|c|c|c|c|}
\hline & Group 1 & Group 2 & Group 3 \\
\hline \multicolumn{4}{|l|}{ Subject-verb-agreement } \\
\hline \multirow[t]{2}{*}{ SVA correctness rate } & $45 / 65$ & $42 / 59$ & $17 / 23$ \\
\hline & 69.2 & 71.2 & 73.9 \\
\hline \multicolumn{4}{|l|}{ Question type } \\
\hline All yes/no & 67 & 44 & 0 \\
\hline with inversion and subject (VSX) & $9(2)$ & $7(1)$ & 0 \\
\hline echo questions (SVX) & $30(3)$ & $17(4)$ & 0 \\
\hline - with verb in the infinitive & 4 & 2 & 0 \\
\hline questions with subject omission & $7(2)$ & 4 & 0 \\
\hline - with verb in the infinitive & 2 & 0 & 0 \\
\hline V3/V4 & 2 & 5 & 0 \\
\hline Vfinal & 1 & 0 & 0 \\
\hline Other & 5 & 4 & 0 \\
\hline All wh- & 14 & 35 & 24 \\
\hline wh with inversion and subject & $6(2)$ & $15(1)$ & 9 \\
\hline - with verb in the infinitive form & 1 & 0 & 0 \\
\hline whSub+V & 1 & $1(1)$ & $5(4)$ \\
\hline wh with subject omission & 1 & $4(2)$ & 0 \\
\hline - with verb in the infinitive form & 1 & 0 & 0 \\
\hline V3/V4 & 0 & 4 & 1 \\
\hline - with verb in the infinitive form & 1 & 2 & 0 \\
\hline Vfinal & 1 & 1 & 1 \\
\hline - with verb in the infinitive form & 0 & 4 & 4 \\
\hline All questions & 81 & 79 & 24 \\
\hline
\end{tabular}

Table 5: Question types in German adult SLA, in brackets: no SVA on verb

\subsection{Yes/no-questions in German adult SLA}

All learners produce yes/no-questions from the beginning of the recordings, but also employ a large number of different constructions. The learners in their first year of exposure to German produce only $16.4 \%$ (11/67) target-like yes/no-questions (20 a,b), and in two cases, SVA is incorrect. Questions without inversion dominate the production with a rate of 55.2\% (37/67), cf. 20 (b). The verb does not necessarily agree with the subject $(20 \mathrm{c})$ in these constructions, and in $9 \%$ of these, the verb appears in the infinitive, a structure very rarely attested in FLA (19 c, f). Furthermore, 11 of 67 questions (16.4\%) lack an overt subject (20 f). Some learners also produce $\mathrm{V} 3 / \mathrm{V} 4$ questions (3\%), with one producing a single question with a verb-final structure.

(20) (a) kennen sie nich? (Rosemarie)

[know you not] 
(b) kennen sie vielleich palma de rio? (Miguel)

[know you possibly palma de rio]

(c) mein schwester kennen nischt bei siemens? (Zita 1)

[my sister know-INF not at siemens]

(d) ein lehrer gibt die ein kommentar? (Ana 1)

[a teacher gives the/her a comment]

(e) und jetzt vielleicht einkaufen die oder buch? (-Sub) (Zita 1)

[and now possibly shop-INF this or book]

In the second year, intonation questions are still preferred over target-language questions (52.3\% versus $18.2 \%)$, and the L2 learners produce questions with subject omissions (9\%) and non-finite verbs $(4.5 \%)$.

(21) (a) habe de(r) die papier? (Zita 2)

[have-1sg he the paper]

(b) verstehs fuer mein schwester? (Zita 2)

[understand-2sg for my sister]

(c) aber ich sagen nich die nummer? (Ana 2)

[but i say-INF not the number]

These learners produce yes/no-questions with great structural variability. Furthermore, they utter a significant number of questions without inversion $(55 \% ; 61 / 101)$. As table 5 reveals, the dominant pattern in yes/no-questions is the SVX-structure. None of the participants produce yes/no-questions in year 3-4.

\subsection{Wh-questions in adult SLA of German}

In the first year of exposure to German, wh-questions are not very frequent (17.2\%) (cf. table 5 and table 6). However, most of them are target-like $(64.3 \%)$, as they appear with the obligatory inversion and with an overt subject. The verbs in these structures are not consistently marked correctly for SVA. Furthermore, and especially for Ana, these inverted structures may be seen as unanalyzed patterns, as in was is $+X$ and wie heiße $(n)+X$ from example 22 (a).
(a) wie heißen die leute? (Ana 1)
wie heiße etwas? (Ana 1)
[how call-INF the people/something]
(b) wie sagen ich? (Zita 1)
[how say-INF I]
(c) warum du sprechen deutschland gut? (Rosemarie)
[why you speak-INF Germany well]
(d) warum du nich deutsche spreche? (Antonio S.)
[why you not German speak]

In these first 12 months of exposure to German, $23.1 \%$ of all questions appear with an infinitive. In the second and third year of German, the productivity of wh-questions increases; V3/V4 as well as V-final sentences are still structural possibilities and occur with verbs in the 
Solveig Chilla and Matthias Bonnesen: A cross-linguistic perspective on questions in German and19 French adult second language acquisition

infinitive form $(17 / 59 ; 22.8 \%)$ and some wh-questions with a finite verb in final position (cf. examples in $23 \mathrm{a}-\mathrm{g})$.

(23) (a) was du machen fueßen? (Zita 2)

[what you make-INF feet]

(b) und dann was arbeitsamt sagen? (Zita 2)

[and then what jobcenter say-INF]

(c) warum du fahrst nicht heute ins kino? (Ana 2)

[why you go-2sg not today to the cinema]

(d) was ich muessen? (Zita 3)

[what I must-INF]

(e) warum nich die samstag oder sonntag machen ein fest oder ein excursion ausflug oder etwas? (Ana 2) (-Sub)

[why not the saturday or sunday make-INF a party or an

excursion or something]

(f) wieviel die ambulancia die polizei bezahlt? (Zita 2)

[how much the ambulance the police pays]

(g) was du bist? (Zita 3)

[what you are]

As in yes/no-questions, L2 learners omit the subject in wh-questions with a rate of up to $17.1 \%(6 / 35)$ in the second year of exposure.

To conclude, adult L2 learners produce several kinds of errors in their acquisition of German yes/no and wh-questions. For an overview of the differences between FLA and adult SLA see table 6.

\begin{tabular}{|c|c|c|}
\hline Grammatical phenomena & FLA & adult SLA \\
\hline \multirow[t]{3}{*}{ word order } & $\begin{array}{l}\text { inversion from the first questions } \\
\text { onwards, structural patterns are } \\
\text { correct from the first occurrences } \\
\text { onwards }\end{array}$ & $\begin{array}{l}\text { yes/no-questions appear without } \\
\text { subject-verb inversion (up to } 50 \% \text { ), } \\
\text { high structural variability }\end{array}$ \\
\hline & $\begin{array}{l}\text { wh-questions appear consistently } \\
\text { with V2 }\end{array}$ & $\begin{array}{l}\text { wh-questions appear with V2, } \\
\text { V3/V4 and V-final }(11.1 \%)\end{array}$ \\
\hline & no V3 or V4 patterns & $\begin{array}{l}\text { V3- and V4-patterns }(\mathrm{wh}=11.1 \% \text {; } \\
\text { yes/no }=6.2 \%)\end{array}$ \\
\hline \multirow[t]{2}{*}{ finiteness } & no subject-verb agreement errors & $\begin{array}{l}\text { verbs in wh-questions do not } \\
\text { necessarily agree with the subject } \\
(13.9 \%)\end{array}$ \\
\hline & no infinitives in wh-questions & infinitives in wh-questions (22.8\%) \\
\hline subject omissions & subject omissions in yes/no- & subject omissions in yes/no- \\
\hline
\end{tabular}




\begin{tabular}{ll}
\hline questions are rare; & questions up to 16.4\%; subject \\
no subject omissions in wh- omission in wh-questions up to \\
questions
\end{tabular}

Table 6: Different types of errors in the acquisition of questions in German FLA and adult SLA

\section{$5 \quad$ Discussion}

The cross-linguistic comparison of the acquisition of questions in German and French offers a new perspective to differences and similarities between FLA and adult SLA. With our analysis, we bring forward both a new analysis of L2 syntax of French, and broaden the perspective to similar SLA interlanguages concerning different second languages. The comparative study on a Germanic and a Romance L2, differing not only in their overall linguistic properties (such as i. e. OV/VO, V2, clitics), but explicitly in the formation and regularities of questions, shows striking similarities in adult SLA, and irrespective of the first and the second languages and of instructed versus non-instructed learning. The investigation of the adult SLA of morphological and structural aspects of questions in French and German strengthens the assumption that the acquisition of morphology and syntax (on the CP-layer) is connected in French and German FLA but is disentangled in adult SLA. By including all whand yes/no-questions in the corpora, we show that learners of both German and French show a high structural variability in their questions formation. From a cross-linguistics perspective, it is astounding that adult SLA of both German and French shows non-target-like structures to a high extent. Moreover, both groups of learners produce questions that should not appear in the (spoken) target language. French, if compared to German, being less rigid in question syntax, seems to be equally difficult for adult SLA, whereas both German and French L1 learners produce hardly any errors. Adult SLA of French and German leads furthermore to antidromic errors: The German L2 learners avoid inversion in yes/no questions (where inversion is obligatory), and the French L2 learners produce sentences with inversion (where it is excluded/ungrammatical). Both groups of adult SLA show difficulties with finiteness on verbs, and produce finite questions without finite verbs. Hence, we found ungrammatical inversions and non-inversions in questions in both languages only in the adult SLA data. They moreover produce subject omission errors in both second languages, and make use of questions that are neither accounted for by transfer from the L1 or the learning contexts. In French, for example, we document a correct or phonetically incorrect form of estce que, all possible word orders with both clitic and non-clitic subjects, and with non-finite verbs. In German, they make use of V3- and V4-questions, and -besides using non-finite verbs in finite contexts- omit the obligatory subject. Obviously, both learners of French and German L2 produce non-target constructions which they probably never heard or read, and, what is even more important, which do not occur in FLA.

Our results are particularly relevant since the L2 contexts of our learner groups are different. The L2 learners of German acquire the language in a natural setting without being instructed, whereas the L2 learners of French are exposed to language teaching. In this respect, one could have expected to obtain different results. However the error types are quite similar in both groups: we find many errors which cannot be accounted for by feature checking as a motivation for movement, such as all possible word orders and no clear distinction between finite and non-finite verbs is attested. This result is in accordance with those of Pienemann (1986), who proposes similar adult SLA patterns for all learners, regardless of their learning context.

With respect to adult SLA modelling, Prévost/White (2000) propose the Missing Surface Inflection Hypothesis (MSIH), claiming that "variability in adult L2 performance does not 
reflect a deeper lack of functional categories or features associated with tense and agreement. Rather, L2 learners have difficulties with the overt realization of morphology" (ibid.: 104), but "syntactic consequences of finiteness are known to learners" (ibid.: 119). As a consequence, both wh- and yes/no questions could bear a verb - in form of an infinitive, a bare stem or as stem +suffix - can appear in a raised position or in situ. Whenever adult L2 leraners produce inflected verbs, these are largely correct and appear in a finite position, because features and feature-checking mechanisms are present - but uninflected verbs may appear in non-finite and finite (raised) positions as well, since they "are not in fact non-finite but are being used as default forms exhibiting properties of finite verbs" (ibid.: 109). In our study, most of the finite verbs in finite positions appear to be finite, indeed. What may be problematic, though, are our cross-linguistic findings about difficulties with question syntax. An evidence generative grammar with movement and checking operations is provided by native language use. The observation that morphological finiteness is located in a specific syntactic position is the basic argument for feature checking in a certain projection (TP, CP). Assuming that subject-verb agreement/finiteness motivates the movement of the verb to a functional category (TP), but postulating on the other hand that this movement also takes place when the verb does not carry the necessary features, as the MSIH states, is questionable. The entire mechanism loses plausibility if morphological finiteness must be visible in FLA, but may remain invisible in adult SLA, i. e. a non-finite verb may finite features. According to the MSIH, the verbs are finite, even though finiteness is morphologically invisible. But even if this claim could be accepted by the fact that adult L2 learners produce most questions with finite verbs, the proposal predicts question syntax being intact. Since only the morphological feature for finiteness is lost in the MSIH, the syntactic position of finiteness should not bar any difficulties for second language learners. Our data of French and German adult SLA however reveal such variability of question syntax, and with the syntactic position of the verb in particular, that an intact $\mathrm{CP}$ is hardly to be accounted for. Instead of discovering the correct position of the verb at a certain stage of acquisition which can be accounted for by parameter setting in FLA, the adult learners gradually approach the target word order but still exhibit a great deal of variation after several years of exposure to the L2. Or data contradict the predictions of the MSIH, for not only morphological features, but syntactic finiteness is problematic in adult SLA. Our adult SLA data can hardly be accounted for by a tree structure of VP-TP-CP and feature checking. Instead, the L2 learners try different positions for the verb, also in later stages of acquisition, which can better be accounted for by a linear phrasal order.

The cross-linguistic perspective on the acquisition of questions in adult SLA shows evidence for a clear-cut difference between FLA and adult SLA in this specific aspect of grammatical development. The low rate of subject clitics and clitic doublings in adult SLA of French can be accounted for by assuming that, in contrast to FLA learners, adult L2 learners do not analyze subject clitics as elements of finiteness. These findings support the view that subject clitics are not analyzed as bound elements but rather as NPs/DPS. As with German, adult L2 learners of French adopt strategies to avoid difficulties with inversion, like omitting the verb. Some always make use of the est-ce que or qu'est-ce que option or employ il y a instead of est-ce que as a question marker when constructing yes/no questions, even without finite verbs. They then simply add an item to a declarative utterance in order to mark it as a question (another strategy to avoid the difficulties with inversion). Qu'est-ce que questions are produced with inversion and with infinite verbs. Both clitic and non-clitic subjects are observed in inversion and intonation questions, and are attested in L2 speech with a variety of word order patterns. The L2 learners employ a variety of structures with a preference for SVO order irrespective of the language. The Impairment Representation Hypothesis (IRH) (Beck 1998; Eubank 1993/1994; among others) accounts for these differences in first and second language acquisition. IRH and FDH mirror our findings, by predicting the use of (domain- 
general) strategies instead of agreement or feature checking mechanisms. This may lead to the conclusion that the adult L2 learners use specific phrasal surface structures (cf. Clahsen et al. 1983) rather than adhering to the restrictions of the target language; that is, the obligatory inversion in questions, which is, in a generative interpretation, motivated by the need for feature checking in a specifier-head-relation in the CP. Assuming that checking mechanisms do not operate in L2, the learners do not need to move the verb to the position before the subject $\left(\mathrm{C}^{\circ}\right)$. The adult SLA learners use non-finite and finite verbs regardless of the syntactic position. This can be considered as further evidence that the learners do not use the same hierarchical structures and feature checking mechanisms as seen in FLA, where the verb is always morphologically finite in an inversion. The connection between syntax and morphology found in FLA is obviously not present in the L2 learners' use.

The learners are aware of lexical categories and certain projections which are used for notions such as subject and object. However, in contrast to FLA, their word order of subject, verb(s), object and wh-phrase is generated by linear rules, as proposed in Clahsen et al. (1983). In the first acquisition stage, they use rules like those in (24) for both declaratives and questions:
(a) $\mathrm{S}>$ (wh) DP VP (DP)
(b) VP>V DPI V PP
(d) $\mathrm{NP}>(\operatorname{Adj} P) \mathrm{N}$
(d) DP $>$ Det NP

1. words

2. SVO

3. ADV

4. SEP

5. INV/Subject-Verb Agreement marking or not (+/- AGR)

6. V-final in subordinate clauses (with verb placement errors) (Pienemann 1998)

Although this kind of phrase-structure-grammar is a common approach to SLA, its implications are still most adequate to the data presented than a movement and feature checking apporach. The rules in (24) account for the L2 learner's awareness that a sentence S is comprised of smaller units such as DPs. Rule (24a) explains why the learners initially do not produce inversions. This stage corresponds with Pienemann's (1998) $4^{\text {th }}$ stage, in which SVO is used exclusively, but in which an element can already precede the subject. In later stages, the learners recognize that a question can have a word order which cannot be generated by rule (24a), thus adding (26):

(26) $\mathrm{Q}>$ (wh) V DP (DP) (Q=Question)

This stage is the $5^{\text {th }}$ stage ("inversion") described in Pienemann (1998). Thus, the attested development is in accordance with his studies. Still, the learners do not incorporate feature checking in their structures. Thus, both finite and non-finite verbs can be inserted in the position V. In contrast, since hierarchical structures are used in FLA in accordance with the CP-TP-VP tree, the errors which could be generated by rules (24) and (26) are excluded. In French, the learners have additional rules stating that est-ce que can be inserted after the whphrase. In contrast, the question morpheme est-ce que occupies $C^{\circ}$ in FLA (Rooryck 1994) with the $\mathrm{CP}$ carrying the question feature. Since inversion is analyzed as the movement of the verb to $\mathrm{C}^{\circ}$, inversion is not possible in est-ce que-questions, the $\mathrm{C}^{\circ}$ position being occupied by the question morpheme. In contrast, the rule-based system in adult SLA allows inversion with est-ce que. 
To conclude, the cross-linguistic comparison of first and second language learning of question syntax and morphology study provided here prevails further evidence for FLA and SLA being fundamentally different, and allows for further discussion of the underlying mechanisms of adult SLA and its modelling.

\section{References}

Bartning, Inge/Schlyter, Suzanne (2004): "Itinéraires acquisitionnels et stades de développment en français L2". Journal of French Language Studies 14: 281-299.

Beck, Maria-Luise (1998): "L2 acquisition and obligatory head movement: English-speaking learners of German and the local impairment hypothesis". Studies in Second Language Acquisition 20: 311-348.

Behnstedt, Peter (1973): Viens-tu? Est-ce que tu viens? Tu viens? Formen und Strukturen des direkten Fragesatzes im Französischen. Tübingen: Narr. (= Tübinger Beiträge zur Linguistik 41).

Bley-Vroman, Robert (1989): "What is the logical problem of foreign language learning?". In: Gass, Susan M./Schachter, Jacquelyn (eds) (1989): Linguistic Perspectives on Second Language Acquisition. Cambridge, Cambridge University Press: 41-68.

Bonnesen, Matthias (2008): Spracheinfluss oder Sprachtrennung an der Schnittstelle SyntaxPragmatik? Der Erwerb der linken Satzperipherie bei Französisch/Deutsch bilingual aufwachsenden Kindern. Saarbrücken: VDM.

Bonnesen, Matthias/Meisel, Jürgen M. (2005): "Die 'Subjekt-Verb Inversion' in: Interrogativkonstruktionen des gesprochenen Französischen: Zum Problem der syntaktischen Variation". In: Kaiser, Gerog A. (ed.) (2005): Deutsche Romanistik generativ. Tübingen, Narr: 31-48.

Chee, Michael W./Tan, Edsel W./Thiel, Thorsten (1999): "Mandarin and English single word processingstudied with functional magnetic resonance imaging". Journal of Neuroscience 19: 3050-3056.

Chomsky, Noam (1957): Syntactic Structures. The Hague: Mouton.

Chomsky, Noam (1986): Knowledge of Language: Its Nature, Origin, and Use. London: Praeger.

Chomsky, Noam (1995): The Minimalist Program. Cambridge, MA: MIT Press.

Clahsen, Harald (1988): "Parametrized grammatical theory and language acquisition. A study of the acquisition of verb placement and inflection by children and adults". In: Flynn, Susanne/O'Neil, Wayne (eds.) (1988): Linguistic Theory in Second Language Acquisition. Dordercht, Kluver: 47-75.

Clahsen, Harald/Meisel, Jürgen M./Pienemann, Manfred (1983): Deutsch als Zweitsprache. Der Spracherwerb ausländischer Arbeiter. Tübingen: Narr.

Clahsen, Harald/Muysken, Pieter (1986): "The accessibility of Universal Grammar to adult and child learners. A study of the acquisition of German word order". Second Language Research 2: 93-119.

Clahsen, Harald/Muysken, Pieter (1989): "The UG paradox in L2 acquisition". Second Language Research 5: 1-29.

Clahsen, Harald/Penke, Martina (1992): "The Acquisition of Agreement Morphology and its Syntactic Consequences: New Evidence on German Child Language from the SimonaCorpus". In: Meisel, Jürgen M. (ed.) (1992): The Acquisition of Verb Placement. Functional Categories and V2 Phenomena in Language Acquisition. Dordrecht, Kluwer: 181-223.

Clahsen, Harald/Penke, Martina/Parodi, Teresa (1993/94): "Functional categories in early child German". Language Acquisition 3: 395-429.

Confais, Jean-Paul (1980): Grammaire Explicative. Ismaning: Max Hueber.

Coveney, Aidan (2002): Variability in spoken French. A sociolinguistic study of interrogation and negation. Bristol: Bank. 
Crisma, Paola (1992): "On the acquisition of Wh-questions in French". Geneva Generative Papers 1: 115-122.

De Cat, Cécile. (2000): "Left- and right dislocations as adjunctions in early child French". Durham and Newcastle Working Papers in Linguistics 60: 47-61.

Den Besten, Hans (1977): "On the interaction of root transformations and lexical deletive rules". Groninger Arbeiten zur Germanistischen Linguistik 20: 1-78.

Diehl, Erika/Chirsten, Helen/Leuenberger, Sandra/Pelvat, Isabelle/Studer, Thérèse (2000): Grammatikunterricht: Alles für der Katz? Untersuchungen zum Zweitspracherwerb Deutsch. Tübingen: Niemeyer.

Eubank, Lynn (1993/1994): "On the transfer of parametric values in L2 development". Language Acquisition 3: 183-208.

Felix, Sascha W. (1978): Linguistische Untersuchungen zum Zweitspracherwerb. München: Fink.

Fritzenschaft, Agnes/Gawlizek-Maiwald, Ira/Tracy, Rosemarie/Winkler, Susanne (1990): "Wege zur komplexen Syntax". Zeitschrift für Sprachwissenschaft 9: 52-134.

Granfeldt, Jonas/Schlyter, Suzanne (2004): "Cliticisation in the acquisition of French as L1 and L2". In: Prévost, Philippe/Paradis, Johanne (eds.) (2004): The acquisition of French in different contexts. Amsterdam/Philadelphia, Benjamins: 333-337.

Hamann, Cornelia (2000): "The acquisition of constituent questions and the requirements of interpretation". In: Friedemann, Marc Aaurel/Rizzi, Luigi (eds.) (2000): The Acquisition of Syntax. London/New York, Longman: 170-201.

Haznedar, Belma (2003): "The Status of Functional Categories in Child Second Language Acquisition: Evidence from the Acquisition of CP". Second Language Research 19: 1-41.

Hernandez, Arturo E./Martinez, Antigona/Kohnert, Kathryn (2000): "In search of the language switch: An fMRI study of picture naming in Spanish-English bilinguals". Brain \& Language 73: 421-431.

Hirschbühler, Paul/Labelle, Marie (1994): Syntaxe du français - L'universel et le particulier dans la langue française. Unpublished manuscript. University of Montréal, Québec.

Hyltenstam, Kenneth/Abrahamsson, Niclas (2003): "Maturational Constraints in SLA". In: Doughty, Catherine J./Long, Michael H. (eds.) (2003): The Handbook of Second Language Acquisition. Malden, MA/Oxford, Blackwell: 539-588.

Ionin, Tania/Wexler, Kenneth (2002): "Why is 'is' easier than '-s'?: acquisition of tense/agreement morphology by child second language learners of English". Second Language Research 18: 95-136.

Jakubowicz, Celia/Strik, Nelleke (2008): "Scope-marking strategies in the acquisition of longdistance wh-questions in French and Dutch". Language and Speech 51, 1/2: 101-131.

Kaiser, Georg (1994): "More about INFLection and agreement. The acquisition of clitic pronouns in French". In: Meisel, Jürgen M. (ed.) (1994): Bilingual First Language Acquisition: French and German Grammatical Development. Amsterdam/Philadelphia, Benjamins: 131-159.

Kaiser, Georg/Meisel, Jürgen M. (1991): "Subjekte und Null-Subjekte im Französischen". In: Fanselow, Gisbert/Olsen, Susan (eds.) (1991): "Det, Comp und Infl": Zur Syntax funktionaler Kategorien und grammatischer Funktionen. Tübingen, Niemeyer: 110-136. (Linguistische Arbeiten 263).

Van Kampen, Nelly Jacqueline (1997): First steps in Wh-movement. PhD-thesis, Utrecht University.

Knudsen, Eric I. (2003): "Early experience and critical periods". In: Squire, Larry R./Berg, Darwin/Bloom, Floyd E./Du Lac, Sascha/Ghosh, Anirvan/Spitzer, Nicholas C. (eds.) (2003): Fundamental neuroscience. Amsterdam, Academic Press: 555-573.

Knudsen Eric I. (2004): "Sensitive periods in the development of the brain and behavior". Journal of Cognitive Neuroscience 16:1412-1425. 
Lardière, Donna (1998): "Dissociating syntax from morphology in a divergent L2 end-state grammar". Second Language Research 14: 359-375.

Lardière, Donna (2003): "Second language knowledge of [+/-past] vs. [+/-finite]". In: Liceras, Juana M./Zobel, Helmut/Goodluck, Helen (eds.) (2003): Proceedings of the 6th Generative Approaches to Second Language Acquisition Conference GASLA 2002. Somerville/MA, Cascadilla: 176-189.

Lenneberg, Eric H. (1967): Biological Foundations of Language. New York: Wiley.

Locke, John L. (1997): "A Theory of Neurolinguistic Development". Brain and Language 58: 265-326.

Meisel, Jürgen M. (1991): "Principles of Universal Grammar and strategies of language use: On some similarities and differences between first and second language acquisition". In: Eubank, Lynn (ed.) (1991): Point, Counter-point: Universal Grammar in the second language acquisition. Amsterdam/Philadelphia, Benjamins: 231-276.

Meisel, Jürgen M. (1995): "Parameters in acquisition". In: Fletcher, Paul/MacWhinney, Brian (eds.) (1995): Handbook of Child Language. Oxford, Blackwell: 10-35.

Meisel, Jürgen M. (1997): "The acquisition of the syntax of negation in French and German: contrasting first and second language development". Second Language Research 13: 227263.

Meisel, Jürgen M. (2007): Exploring the limits of the LAD. A collection of four papers. Hamburg. (= Working Papers in Multilingualism 80).

Meisel, Jürgen M. (2008): "Child second language acquisition or successive first language acquisition?". In: Haznedar Belma/Gavruseva, Elena (eds.) (2008): Current trends in childsecond language acquisition. Amsterdam/Philadelphia, Benjamins: 55-80.

Meisel, Jürgen M. (2009): "Second language acquisition in early childhood. Resources to sustain or remove epistemic asymmetry". Zeitschrift für Sprachwissenschaft. Themenheft 28/1: 5-34.

Meisel, Jürgen M./Elsig, Martin/Bonnesen, Matthias (2011): "Delayed grammatical acquisition in first language development: subject-verb inversion and subject clitics in French interrogatives". Linguistic Approaches to Bilingualism 1/4: 347-390.

Müller, Natascha (1993): Komplexe Sätze. Der Erwerb von COMP und von Wortstellungsmustern bei bilingualen Kindern (Französisch/Deutsch). Tübingen: Narr.

Myles, Florence (2001-2002): http://www.flloc.soton.ac.uk/newcastle/index.html, accessed December 14, 2012.

Oiry, Magda/ Demirdache, Hamida (2006): "Evidence from L1 acquisition for the syntax of wh-scope marking in French". In: Torrens, Vincent/Escobar, Linda (eds.) (2006): The Acquisition of Syntax in Romance Languages. Amsterdam/Philadelphia, Benjamin: 289318.

Parodi, Teresa (1998): Der Erwerb funktionaler Kategorien im Deutschen. Eine Untersuchung zum bilingualen Erstspracherwerb und zum Zweitspracherwerb. Tübingen: Narr.

Pienemann, Manfred (1986): "Is language teachable?". Applied Linguistics 10: 52-79.

Pienemann, Manfred (1998): Language Processing and Second Language Development. Processability Theory. Amsterdam/Philadelphia, Benjamins.

Prévost, Philippe (1997): Truncation in second language acquisition. Ph.D. Dissertation, McGill University.

Prévost, Philippe (2009): The Acquisition of French. The Development of Inflectional Morphology and Syntax in L1 Acquisition, Bilingualism and L2 Acquisition. Amsterdam/Philadelphia: Benjamins.

Prévost, Philippe/White, Lydia (2000): "Missing Surface Inflection or Impairment in second language acquisition? Evidence from tense and agreement". Second Language Research 16/2: 103-133. 
Rizzi, Luigi (1992): "Early null subjects and root null subjects". Geneva Generative Papers 1: 102-114.

Rizzi, Luigi (1996): "Residual verb second and the Wh-criterion". In: Belletti, Adriana/Rizzi, Luigi (eds.) (1996): Parameters and Functional Heads. Essays in Comparative Syntax. Oxford, Oxford University Press: 63-99.

Rizzi, Luigi/Roberts, Ian (1989): "Complex inversion in French". Probus 1: 1-33.

Roberge, Yves (1986): "On doubling and null argument languages". Proceedings of the North Eastern Linguistic Society 16: 388-402.

Rooryck, Johan (1994): "On two types of underspecification: Towards a feature theory shared by syntax and phonology". Probus 6: 207-233.

Rothweiler, Monika (1993): Der Erwerb von Nebensätzen im Deutschen. Eine Pilotstudie. Tübingen: Niemeyer.

Rothweiler, Monika (2006): "The acquisition of V2 and subordinate clauses in early successive acquisition of German". In: Lleó, Conxita (ed.) (2006): Interfaces in multilingualism: Acquisition, representation and processing. Amsterdam/Philadelphia, Benjamins: 91-113.

Rüschemeyer Shirley-Ann/Fiebach, Christian/Kempe, Vera/Friederici, Angela, D (2005): "Processing lexical semantic and syntactic information in first and second language: fMRI evidence from German and Russian". Human Brain Mapping 25: 266-286.

Sankoff, Gillian (1982): "Usage linguistique et grammaticalisation: Les clitiques sujets en français". In: Dittmar, Norbert/Schlieben-Lange, Brigitte (eds.) (1982): Die Soziolinguistik in romanischsprachigen Ländern. Tübingen, Narr: 81-85.

Saur, Dorothee/Baumgaertner, Annette/Moehring, Anja/Büchel, Christian/Bonnesen, Matthias/Rose, Michael/Musso, Mariachristina/Meisel, Jürgen M. (2009): "Word order processing in the bilingual brain". Neuropsychologia 47: 158-168.

Tracy, Rosemarie (1994): "Raising questions: Formal and functional aspects of the acquisition of Wh-questions in German". In: Tracy, Rosemarie/Lattney, Elsa (eds.) (1994): How Tolerant is Universal Grammar? Essays on Language Learnability and Language Variation. Tübingen: Niemeyer.

Tracy, Rosemarie (2009): "Beyond maturation". Zeitschrift für Sprachwissenschaft 28: 59-67.

Wartenburger, Isabell/Heekeren, Hauke R./Abutalebi, Jubin/Cappa, Stefano F./Villringer, Arno/Perani, Daniela (2003): "Early setting of grammatical processing in the bilingual brain". Neuron 37: 159-170.

Wexler, Kenneth (1994): "Optional infinitives, head movement and the economy of derivations". In: Lightfoot, David/Hornstein, Norbert (eds.) (1994): Verb movement. Cambridge, Cambridge University Press: 305-351.

White, Lydia (2003): Second language acquisition and Universal Grammar. Cambridge: Cambridge University Press.

Wode, Henning (1983): "Some stages in the acquisition of questions by monolingual children". In: Wode, Henning (ed.) (1983): Papers on Language Acquisition, Language Learning and Language Teaching. Heidelberg, Groos: 47-93.

Zisa Group (1983-1985): Exkurs zur Interrogation. Unpublished Manuscript. University of Hamburg.

Zuckerman, Shalom/Hulk, Aafke (2001): "Acquiring optionality in French Wh-questions. An experimental study". Revue Québécoise de Linguistique 30, 2: 71-97. 